\title{
Over-occupancy in London's acute psychiatric units - fact or fiction?
}

\author{
Bernard Audini, Richard Duffett, Paul Lelliott, Alison Pearce \\ and Catherine Ayres
}

\begin{abstract}
Aims and method Inner London psychiatric services face particular pressures. One measure of this is overoccupancy of acute psychiatric beds. Seven censusbased surveys were conducted between June 1994 and January 1999 to quantify and monitor problems of inner London acute psychiatric bed provision. The censuses involved 14 inner London mental health services with a combined catchment population of approximately three million. Measures included levels (and changes over time) of occupancy, detention under the Mental Health Act, prolonged hospital stays and ward violence.

Recults 'Minimum' occupancy levels for the combined services were above $100 \%$ at all census points. Occupancy level fell from $122 \%$ to $112 \%$ between the first and seventh census. This was associated with an increase in bed numbers of 2.5 per 100000 . Levels of detention were consistently at around $50 \%$ and violent incidents were high at all census points. Conclusions Current provision of acute beds remains insufficient to meet service demand. To meet the $85 \%$ ward occupancy level recommended by the Royal College of Psychiatrists a further 14 beds or community alternatives per 100000 population would be required.
\end{abstract}

The problems of providing acute psychiatric care in London have been highlighted by a number of commentators (Coid, 1994; Shepherd et al, 1997), a series of inquiries into failures of psychiatric care (Ritchie et al, 1994; Hughes, 1995) and the recent report of the King's Fund Commission London (Johnson et al, 1998).

Between 1954 and 1993, the number of psychiatric beds in England fell by $74 \%$ (Johnson \& Lelliott, 1998). This change has primarily resulted from the closure of long-stay hospitals. Since the closure programme those who have become severely and chronically mentally ill have placed a great burden on acute psychiatric services (Lelliott \& Wing, 1994). This group of patients includes a large and increasing number of young men with schizophrenia (Johnson \& Lelliott, 1998).
In London and elsewhere, bed occupancy levels often exceed $100 \%$ as patients are sent on leave to create beds for other patients who urgently require admission. Even with this undesirable practice, patients are admitted as extra-contractual referrals (ECRs) to beds outside their catchment area trust (Monitoring Inner London Mental Illness Services Project Group, 1995).

Since June 1994, the group Monitoring Inner London Mental Illness Services (MILMIS), coordinated by the Royal College of Psychiatrists' Research Unit, has conducted seven censusbased surveys (MILMIS Project Group, 1995); four at six-month intervals from June 1994 to January 1996, and three at annual intervals during the month of January (January 1997. 1998 and 1999). These provide information on both the extent of the problem and the number of additional beds required if the recommended $85 \%$ occupancy level for catchment area services is to be achieved (Working Party for Social and Community Psychiatry of the Royal College of Psychiatrists, 1988).

\section{The study}

In addition to the members of the research unit. the MILMIS group comprises senior clinical representatives from 14 inner London psychiatric trusts. The group initially comprised 12 trusts however, following the first survey, one service was subsequently divided into two trusts and following the sixth MILMIS survey the only inner London trust not previously participating was included. The services have a combined catchment population of 3.1 million covering approximately the area bounded by London's North and South Circular Roads.

MILMIS surveys have two parts, a census day and a census week prior to or following the census day. At midnight on the census day the number of acute psychiatric beds available to each service is recorded, together with the number of people registered as being in-patients 
on acute psychiatric wards. Patients registered as being in-patients include those on leave, thus the number of in-patients could exceed the number of available beds. For each in-patient, status under the Mental Health Act 1983 is determined together with whether or not they are on leave and the amount of time they have been on the ward.

In addition a count is made of number and location of people who are waiting admission to an acute psychiatric ward managed by participating services. These people might be waiting in a non-acute psychiatric ward, a medical ward, an acute psychiatric ward in another trust, a private psychiatric hospital, a community setting, a police cell or a prison. Efforts are made to ensure patients are not counted twice within the same trust, however some patients admitted to neighbouring MILMIS trusts may have been counted by both the host and catchment area trust.

During the census week, the number of incidents of violence, sexual harassment and self-harm occurring on the acute wards were counted. Incidents of violence were divided into three categories: (a) 'first-degree', which result in no detectable injury; (b) 'second-degree', which result in minor physical injuries such as bruising, grazes or small lacerations; (c) 'third-degree', which result in major physical injuries including large lacerations, fractures, loss of consciousness or any assault requiring subsequent medical investigation.

For the purpose of the MILMIS surveys, an 'acute bed' is defined as a bed designated for the admission of general adult psychiatric patients under the age of 65 years. The great majority of MILMIS services are sectorised with acute beds identified for admission of people from a defined geographical area. Beds in locked psychiatric wards are included if they provide short-term care for patients from a defined sector, but not if they are primarily for forensic patients. Rehabilitation or continuing care beds are excluded as such beds are effectively for tertiary referrals and do not usually admit patients directly from the community. Beds are excluded if they are designated as offering specialist services, for example, for drug detoxification or for the treatment of eating disorders, even if they are located within an acute ward.

The survey instrument was piloted during the first census in June 1994 (MILMIS I). The pilot highlighted inconsistencies in defining an acute bed'. The definitions were tightened and there was regular telephone monitoring during MILMIS II, (January 1995) and all subsequent surveys. Following MILMIS II and III an independent researcher visited services chosen at random to check on data accuracy (four and six services respectively). These 'validity' checks revealed continuing minor discrepancies between data collectors particularly in the definition of 'acute bed'. These resulted from the blurring of boundaries in some services between acute and rehabilitation wards and the involvement of different staff in the collection of data (this has been estimated to account for a maximum of $2 \%$ of bed numbers). Immediately prior to MILMIS IV (January 1996), two members of the College Research Unit visited all sites to ensure that data were collected in a standard way. New data collectors were visited and trained prior to MILMIS V (January 1997), and two researchers visited all sites to assess data collection methods following MILMIS VI (January 1998). All new data collectors were trained in methods of data recording. Despite the checks one service had severe problems with data collection and was omitted from all analyses (MILMIS VII). The full MILMIS group met on 10 occasions to discuss the data collection method and results.

\section{Calculating bed requirement}

To quantify the extent of this unmet need for acute beds, occupancy rates were calculated in three different ways using three different numerators, and expressed as a percentage of the total number of acute beds (denominator):

(a) 'True' occupancy: numerator=number registered as in-patients (Row 5, Table 1) plus those who are awaiting admission (Rows 12-17).

(b) 'Ward' occupancy: numerator=the total number registered as in-patients (Row 5).

(c) 'Minimum' occupancy: numerator=number registered as in-patients (Row 5) minus those on leave who were not thought to need a bed kept available (Row 11), plus those for whom a bed is required but who are placed elsewhere because no acute bed is available locally (Rows 12-17).

Each definition of occupancy makes its own contribution to describing the use of beds. 'True' occupancy provides information about the number of beds required to meet the needs of all patients who should be accommodated on that day. 'Ward' occupancy relates to the number of patients whose care is the responsibility of the ward staff. Ideally a bed should always be available for each of these patients. 'Minimum' occupancy provides an absolute measure. A 'minimum' occupancy of greater than $100 \%$ indicates that care is unsafe and/or unsupportive because beds are not available to patients who need them that day. 
Table 1. Results of the seven MILMIS censuses conducted between June 1994 and January 1999

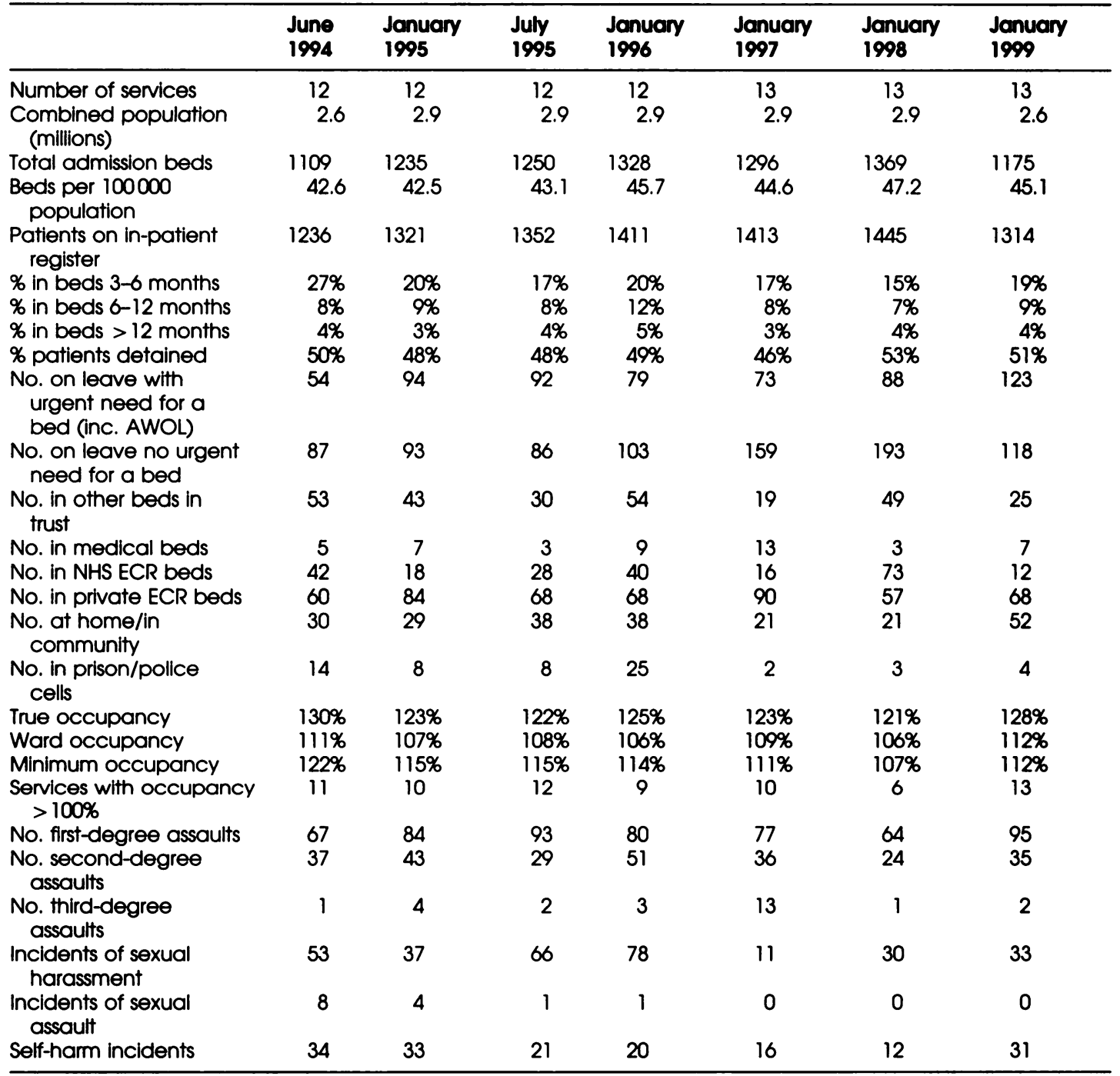

AWOL absent without leave; ECRs, extra-contractual referrals.

\section{Findings}

The results of the seven MILMIS surveys are summarised in Table 1.

\section{Bed provision}

The 13 services which had returned data had a mean of 45.1 acute beds per 100000 population at the time of MILMIS VII (range 24-109). Bed provision did not correlate significantly with the social deprivation levels of participating services as measured by Jarman UPA8 Scores (Jarman, 1983).

The smaller catchment population and the lower bed numbers in MILMIS I survey is accounted for by data being captured for only a part of the catchment area in one of the 12 services. The rise in numbers of beds between MILMIS I and MILMIS VI is largely accounted for by eight services, which increased acute bed provision. The fall in bed numbers for MILMIS VII are due to two services - one failed to return data and the other changed its service configuration with a transfer of some beds from acute to a rehabilitation service.

Use of alternatives to local acute beds

Patients awaiting urgent admission or transfer to an inner London acute bed were in a variety of 
settings. Some had been admitted elsewhere as ECRs (range for MILMIS I-VII=80-130); some were in other types of psychiatric ward (range 19-54); general medical wards (range 3-13); at home or in another community setting (range 21-52) and in prison or a police cell (range 2-25).

In most services, at all time points, acute bed provision has been inadequate to meet demand. At the time of MILMIS I, all but one service had 'minimum' occupancy levels above $100 \%$ (mean $122 \%$, range 97-153\%); at MILMIS VII five services had minimum occupancy levels below $100 \%$ (mean $112 \%$, range $72-157 \%$ ). Four of six trusts which had increased acute beds, between MILMIS II and VII, also had a fall in 'minimum' occupancy levels between these two census points. Only one of the other seven trusts showed a decrease in 'minimum' occupancy levels.

\section{Ward conditions}

As Table 1 shows, between 27 and 39\% of acute beds on MILMIS census days were occupied by patients who had been in hospital for more than three months. Another consistent finding is that one-half of patients were detained under Sections of the Mental Health Act 1983. Incidents of violence and sexual harassment were very common.

\section{Discussion}

This study is limited in that it has only focused on acute bed provision and has ignored other inpatient facilities and community alternatives to admission. Between 1994 and 1999 there were consistently more patients requiring acute inpatient care than there were beds avallable.

Despite the shortcomings in the methodology of the earlier surveys the results are consistent in showing there are fewer acute psychiatric beds in London than there are patients who require them.

The consequences of this are three-fold:

(a) The quality of care is compromised by admitting patients to hospitals distant from their homes, discharging or sending patients on leave early and not admitting others.

(b) The difficulty of admitting patients when needed puts pressure on community services.

(c) The high use of ECRs results in a transfer of funds away from already hard pressed inner London services.

This leads to poor quality of care and is not cost effective. The widespread use of ECR provision diverts funding from community mental health teams and interrupts continuity of care when patients are admitted to distant services.
Paradoxically, this might increase the demand for beds (Tyrer et al, 1998).

During the period of the seven MILMIS surveys the overall number of acute psychiatric beds in inner London rose by $6 \%$ (from 42.6 to 45.1 per 100000 ) and the overall 'minimum' occupancy level has fallen (from 122 to $112 \%$ ). The relationship between bed numbers and occupancy levels in individual services however is not clear cut; one of the five, which increased bed numbers, did not achieve reduced occupancy levels.

Other factors, not measured by MILMIS, might have affected bed usage during the period of the censuses. These include local service developments which might be alternatives to admission such as assertive outreach and out of hours teams, 24-hour staffed accommodation and respite facilities.

The MILMIS data allow for estimates to be made of the number of additional admission beds, or community alternatives, required to meet a target mean occupancy level of $85 \%$. At MILMIS I the requirement was 19 beds per 100000 population; at MILMIS VII it had reduced to 14 beds.

The MILMIS censuses offer a way of monitoring the impact of policy and service development initiatives at a local and London wide level. In particular, they give some indication of the extent of alternative or additional services required to reduce pressures on acute beds to acceptable levels. These new developments might be additional beds or community alternatives to hospital care. The latter will include assertive community teams, 24-hour nursed beds and bed management initiatives leading to diversions from admission.

MILMIS censuses will continue throughout the period of implementation of the Mental Health Strategy and National Service Framework.

\section{Acknowledgements}

The following are members of the MILMIS group: Professor Peter Tyrer, Professor Malcolm Weller, Dr David Roy, Dr Jed Boardman. Dr Gabrielle Faire, Dr Anna Higgitt, Dr Frank Holloway, Dr Peter Jarrett, Dr Andrew Kent, Dr Steven Pilling, Dr Heather McKee, Dr Stirling Moorey and Dr Eleni Palazidou.

\section{References}

CoID, J. (1994) Failure in community care: psychiatry's dilemma. British Medical Journal, S08, 805-806.

HuGHES, J. (1995) Independent Panel of Inquiry into the Circumstances Surrounding the Deaths of Ellen and Alan Boland. Report to the City of Westminster, the Kensington. Chelsea and Westminster Health Authorities and the North West London Mental Health NHS Trust. London: North West London Mental Health NHS Trust. 
JARMAN, B. (1983) Identification of under privileged areas. British Medical Journal, 286. 1705-1709.

JoHnSON, S., RAMSAY, R., THORNICROFT, G., et al (1998) London's Mental Health. London: King's Fund.

- \& LELUOT, P. (1998) Mental health services in London: evidence from research and routine data. In London's Mental Health (eds S. Johnson. R. Ramsay, G. Thornicroft, et al. pp. 167-192. London: King's Fund.

LELUOTT, P. \& WING, J. (1994) A national audit of new longstay patients. II. Impact on services. British Journal of Psychiatry, 166, 170-179.

Milmis ProJect Group (1995) Monitoring inner London mental lliness services. Psychiatric Bulletin. 19. 276-280.

RirchiE, J., Dick, D. \& Lingham. R. (1994) The Report of the Enquiry into the Care and Treatment of Christopher Clunis. London: HMSO.

SHePHerd, G., BeadsmoOre, A., MoORE, C., et al (1997) Relation between bed use, social deprtvation, and overall bed availability in acute adult psychiatric units, and alternative residential options: a crosssectional survey, one day census data, and stafi interviews. British Medical Joumal, 314, 262-266.

TYRER, P., Evans, K., GANDHI, N., et al (1998) Randomised controlled trial of two models of care for discharged psychlatric patients. British Medical Joumal. 316. 106-109.

WORKING PARTY OF THE SECTION FOR SOCLAL AND COMMUNITY PSYCHIATRY OF THE ROYAL COLlEGE OF PSYCHIATRISTS (1988) Psychiatric Beds and Resources: Factors Influencing Bed Use and Service Planning. London: Gaskell.

Bernard Audini, Research Fellow, Richard Duffett, Former Research Fellow, Paul Lelliott. Director, Alison Pearce, Former Research Assistant, Catherine Ayres, Research Assistant, Royal College of Psychiatrists Research Unit, 11 Grosvenor Crescent, London SWIX 7EE

\title{
Effect of treatment in an active rehabilitation hostel on the need for hospital treatment
}

\author{
Rob Macpherson and Julian Butler
}

\begin{abstract}
Aims and method To describe the work of the 'Vron'. a seven-bed active rehabilltation hostel which has operated in Gloucester for the last 15 years. Such units have been acknowledged as a successful alternative to hospital care for patients with severe mental illness, but nationally are grossly under-provided.

Results Demographic details, admission and discharge data were described for all 103 patients admitted over a 12-year period up to January 1996. Duration of hospital treatment fell from mean 105.8 days one year before and 138.0 days two years before admission to the Vron to: mean 28.6 days one year after and 57.1 days two years after discharge from the Vron. The change was highly significant for both one and two year analyses.

Clinical Implications Residential rehabilitation, provided as part of a comprehensive rehabilitation senvice, was effective at reducing requirement for hospital care. Clinical approaches which contributed to this success were described. The results point to the value of a range of residential hostels, which can through skilled deployment effectively target individual needs for a wide ranging, heterogeneous population.
\end{abstract}

The mental hospital closure programme has been associated with the development of a range of residential community facilities. The rehabilitation hostel, also known as the 'ward in a street', has been recognised in recent reviews (Shepherd. 1991: Young, 1991) and by the Department of Health (1996) as an effective alternative to hospital care for the 'new long-stay' patient. Although such units were generally set up to provide long-term care, studies have consistently shown their success in rehabilitating even the most difficult patients with challenging behaviour, into less dependent settings (see Wykes \& Wing, 1982; Shepherd et al, 1994; Reid \& Garrety, 1996).

In more recent years, descriptions have appeared in the literature of hostels providing more explicitly "fast stream rehabilitation" (Simpson \& Middleton, 1994), or "targeting patients with the greatest chance of rehabilitation" (Shepherd et al, 1994). Such units, adopting a more active rehabilitation approach of deliberately shorter duration, may intervene earlier in the patient's illness history, aiming to 